\title{
Creating Together!
}

\section{The Creation of Learning Tools for Students with Severe and Profound Intellectual and/or Multiple Disabilities}

\author{
Jana Kadastik ${ }^{1}$ MA; Tiia Artla ${ }^{2}$ MA \\ Tallinn University, Estonia \\ janajana@tlu.ee ${ }^{1}$; tiiartla@tlu.ee ${ }^{2}$
}

\begin{abstract}
The study aimed to solve the problem of learning tools for pupils with severe or profound intellectual and/or multiple disabilities (SPIMD). The aim of the study was to evaluate existing learning tools and to create, in cooperation with designers, prototypes for learning tools. The study has been structured as design research. The principle of user-centered design is applied. The existing learning tools and new tools were assessed by specialists working with pupils with SPIMD on a daily basis. The data collection involved observation, a focus group study, a questionnaire. The responses were analysed by performing qualitative content analysis. It appeared that the existing learning tools cannot provide clear and strong stimuli for the pupil. Toys designed for babies and infants are being used as learning tools. The tools are often of poor quality and unreliable, and they cannot be adapted to the special needs of the pupil. Based on the results of the study, it can be concluded that a learning tool which has an unsuitable design (visual, tactile as well as auditive) does not support the understanding of things being taught. In creating new learning tools, it should be taken into account that the product has to be of high quality and reliable; it has to consider the special characteristics of the cognitive processes and the underdeveloped motor skills of the pupils with SPIMD; it has to be universal, allowing adjustments according to individual special needs; it has to be easy to clean.
\end{abstract}

Keywords: multiple disabilities, user-centered design, learning tools, special education, school education.

\section{Introduction}

Many children with special needs can learn to master skills when they live in environments that strongly support their learning and development (Fischer, 2009). Each person is unique and if we follow their lead, we will be able to design a curriculum and teaching approaches that will be right for each one of them (Colley, 2013). It is impossible to give such advice for the creation of learning tools that would apply to all persons and situations. Only general principles to consider can be pointed out. The learning tools have to be adjusted to take into consideration individual needs and different situations. The study aimed to solve the problem of learning tools for pupils with severe or profound intellectual and/or multiple disabilities (SPIMD).

The term SPIMD is used differently in different countries, and it can also have varied meanings. In Estonia, there is a special term care education ("hooldusõpe") referring to teaching pupils with severe and profound disability. In English, several terms are employed. However, recently the terminology has been unified and the main terms used are profound intellectual and multiple disabilities (PIMD) and profound and multiple learning disabilities (PMLD). In this article the author uses the terms: pupils with SPIMD, PIMD and PMLD, which all correspond to the Estonian term. It is very difficult to characterize a person with PIMD because there are two key defining characteristics: profound intellectual disability and profound motor disability, that mean a "multiple disability" is attributed to every individual with more than one discernible disability in executing functions (Nakken, Vlaskamp, 2007). Personal characteristics for the purpose of this study are defined as diagnoses, disabilities, impairments, activity restrictions and other characteristics which represent a person with PIMD. G. Bellamy carried out a study to define PMLD, according to the study, people with PMLD can be defined as follows (Bellamy et al., 2010):

- have extremely delayed intellectual and social functioning;

- may have limited ability to engage verbally, but respond to cues within their environment (e.g. familiar voice, touch, gestures);

- often require those who are familiar with them to interpret their communication intent;

- frequently have an associated medical condition which may include neurological problems, and physical or sensory impairments; 
- they have the chance to engage and to achieve their optimum potential in a highly structured environment with constant support and an individualized relationship with a career.

By the WHO ICD-10 Classification of Mental and Behavioural Disorders (World Health Organization, 2014) people with profound mental retardation IQ under 20 (in adults, mental age below 3 years) are severe limitation in self-care, continence, communication and mobility. Research has shown that all people with profound disability should be considered partially sighted until it has been proven otherwise. Likewise, up to $30 \%$ of them may experience hearing impairment and more than $20 \%$ may suffer from combined sensory impairment (Van Splunder et al., 2006; Broek et al., 2006; Evenhuis et al., 2001).

People with PIMD form a small, but significant section of the wider population of people with intellectual disabilities (Carnaby, 2007). In Estonia SPIMD children (age 3-7) study in special nursery schools. At age 7-21 they can study in special schools, in special classes, and home-schooling is also available. In 2011-2017 the number of pupils with SPIMD, which were attending basic schools and/or home-schooling in Estonia, has been between 229 to 278. (Estonian Education Information System..., 2018). The curriculum for their studies was approved in 2010 as an appendix to the simplified curriculum of the basic school (Pohikooli lihtsustatud riiklik..., 2010). Pupils with PIMD have been taught in Estonia for over ten years. The working draft of the curriculum as compiled by the Centre for Curriculum Development at Tartu University was used before 2010 as the basis. Before the past ten years only the social system dealt with children with PIMD.

According to the simplified curriculum of the Estonian basic school, the aim of teaching children with SPIMD is to preserve and develop the existing functions and skills that possesses and to ensure the child's development in the direction of greater independence, according to the child's potential, and in a familiar environment. The aim of the development is to support the formation of members of the society/citizens who, according to their level of development, learn to perceive their body, are able to notice and communicate their basic needs and wishes, and within the limits of their abilities are able to satisfy these needs either independently or with support (Pohikooli lihtsustatud riiklik..., 2010).

It is impossible to give such advice for the creation of learning tools that would apply to all persons and situations. Only general principles to consider can be pointed out. The learning tools have to be adjusted to take into consideration individual needs and different situations. Creation of learning tools has to be treated as a user-centred design process. User-centred design is primary applied in the development of IT-related products, but the creation of learning tools for children with special needs should also be treated as a process of user-centred design. It follows the principle that designers should create products that suit the users of these products, and not the other way around. User-centered design is based on the principle that 'the user knows the best'. It means primarily that the users are aware of their needs, preferences and aims, and the task of the designer is to design according to these (Safter, 2007, 31). When working with children with SPIMD, the primary assessor of the users' needs is the teacher or the therapist who is working with the children.

The International Organization of Standartization (ISO) (Human centred design..., 2010) identifies main activities of user-centred design, that are: plan the design process; understand and specify the context of use; specify the user requirements; produce design solutions to meet user requirements; evaluate the designs against requirements, designed solution meets user requirements (Rebelo, Soares, 2012, 106). The same principles should be followed in creating learning tools for SPIMD. First, we should examine the term learning tool that is used in this paper. In previous works, the terms educational or pedagogic toy (Brodin, 1999), special toy (Murphy, Carr, Callias, 1986) and play materials (Doctoroff, 2001) have been used, as learning takes place through playful activities. As nowadays, SPIMD students are included in the educational system, the author finds the use of the term learning tools more appropriate, as these are indeed tools used in the learning process. The article an overview of a study, that was triggered by the real-life problem that the needs of the pupils with SPIMD have not been considered are not in creating learning tools for them.

The aim of the study is to evaluate existing learning tools and to create, in cooperation with designers, prototypes for new learning tools. Since in working with children with SPIMD the primary evaluator of the user needs is the teacher or the therapist, in the current study focuses on investigating the assessments of specialists. In the study, the user-centred approach is used, which by its nature is a design study characterised by cycles. The current study can be viewed as the first cycle in the user-centred approach (Figure 1). 


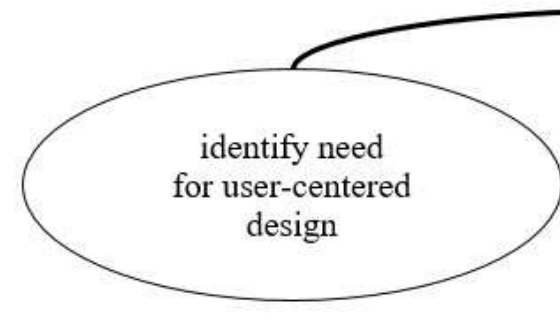

the establishment of a theoretical base which deals with the behaviour, cognition and special needs of pupils with SPIMD

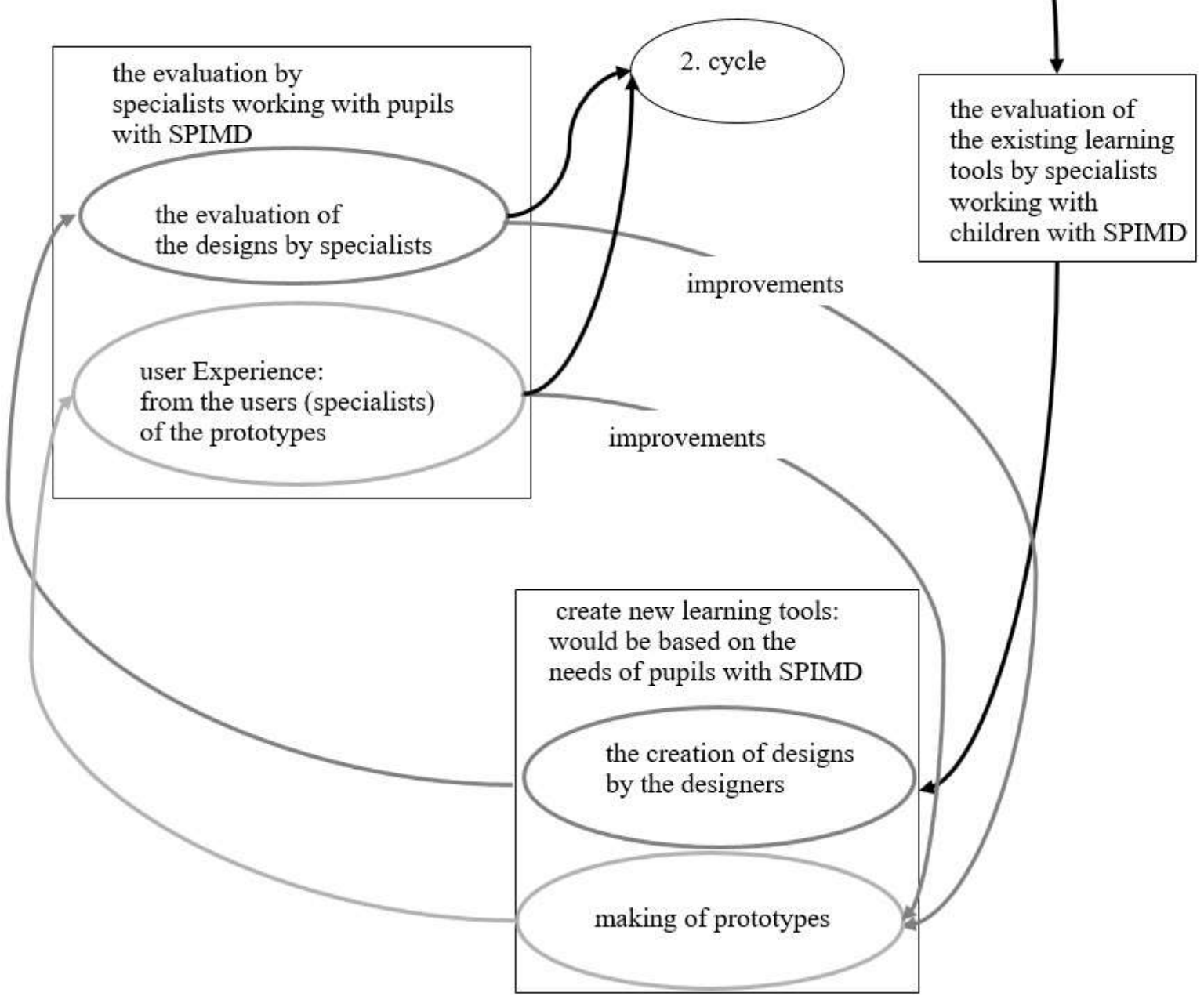

Figure 1. The first cycle in the user-centred approach

(figure by author J. Kadastik on the basis of (Human centred design..., 2010)).

Following the aims of the research, the design process consisted of six stages: The establishment of a theoretical base which deals with the behaviour, cognition and special needs of pupils with SPIMD; The evaluation of the existing learning tools by specialists working with children with SPIMD. Study visits to schools providing education for children with SPIMD were organized for the designers of learning tools; the creation of designs by the designers; the evaluation of the designs by specialists working with pupils with SPIMD; the making of prototypes and using them in the rehabilitation unit of Tallinn Children's Hospital (TCH); feedback from the users of the prototypes.

\section{Methodology}

The study has been structured as design research. The principle of user-centred design is applied. The research was set up as consisting of the following tasks: the evaluation of existing learning tools (Study 1); developing designs for learning tools for pupils with SPIMD (Study 2); carrying out a study in which specialists working with pupils with SPIMD assess the designs (Study 3), use then the prototypes based on the designs and give feedback on these prototypes (Study 4). The sample consisted of specialists who work 
with children with SPIMD on a daily basis. The specialists work in schools providing education for pupils with SPIMD, and in TCH. The study involved eight 3rd year students of textile design at the Estonian Academy of Arts (EAA) who participated in the course: "Interactive learning tools". During the course the students developed designs for learning tools for children with SPIMD.

\section{Study 1: the evaluation of existing learning tools}

A focus group study and a questionnaire were carried out among the specialists dealing with pupils with SPIMD, the aim of which was to assess the existing learning tools. Specialists of five schools and TCH responded. At Tallinn boarding school No. 1, which has the largest number of pupils with SPIMD, the study was carried out as a focus group interview. The specialists of other schools and TCH responded to a questionnaire. The questionnaires were sent electronically. Such an approach made it possible to ask identical questions in the focus group and in the questionnaire. The questions focused on the existing learning tools which support the development of children's visual, auditive and tactile skills. The eight students of textile design at the EAA who participated in the study made two study visits to learn about the current learning tools of the Tallinn boarding school No.1 and observed the classes. In the responses of all specialists participating in the study the similarity of currently used learning tools became apparent. We can distinguish three groups of tools that are used in the development of cognitive skills: musical instruments, toys and self-made learning tools. Musical instruments are the most popular sound-making learning tools. Toys are widely used to develop visual and auditive skills. Toys help to teach the cause and effect relationship. The problem with the toys are that they are not age-appropriate (meant for babies and infants), and their quality is poor. In the focus group unsuitable colours and design were mentioned. The toys are 'too colourful' and of unsuitable colour (a blue bear, pink elephant). In the photos and pictures the figures do not stand out from the background. Regarding auditive toys, bad sound quality and the lacking possibility to regulate the volume were emphasised. Products for infants have often very small buttons and switches which make them hard or impossible to use for children with SPIMD (inadequate/deficient fine motor skills and a considerably larger hand size compared to infants). Pupils experience difficulties in grasping and holding such tools. Many pupils with SPIDM have uncontrollable salivation, or the pupils try to 'stick things in their mouth and bite them'. Bearing this in mind, the learning tools should be of very good quality and easy to clean.

The third-year students of textile design at the EAA emphasised, similarly to the specialists, the poor quality of the currently used toys: ,actually it's not just the problem of the school, rather a general thing about toys- screaming, whining things with unclear functions". Students highlighted the teachers' resourcefulness in using very simple self-made things as learning tools: "bottles of hot and cold water, tactile tools", ,a stand with the caps of juice cartons which the child had to screw on and off'. The students thought that "the existing learning tools could be improved by materials and some new solutions and made easier to handle". Based on the results of the study, in the creation of new learning tools the following aspects should be taken into consideration: 1) the special characteristics of the cognitive processes of the pupils with SPIMD (for example, in distinguishing different sensory stimuli; 2) the buttons, switches and fastenings used have to be usable given the deficient fine motor skills; 3 ) the learning tool has to be of high quality and reliable; 4) the learning tool has to be universal, allowing for adaptations according to individual special needs; 5) the learning tool has to be easy to clean.

Based on the results of the study, it may be concluded that a learning tool whose design (visual, tactile as well as auditive) is unsuitable does not support the understanding of what is being taught ,a nice wooden stand where a child can put domestic animals back to their places (and learn from that). Some other object suddenly pop-out among the animals, and now you cannot teach the child to generalize about domestic animals". The study confirms the need to take into consideration the special characteristics of the development of cognitive processes of pupils with SPIMD, and the need to follow the principles of user-centred and universal design in creating learning tools.

\section{Study 2: designs for new learning tools}

The designs were created by the third-year students of textile design at the EAA who participated in the course „Interactive learning tools”. Eight students participated. The course had two supervisors (Kart Ojavee and Jana Kadastik) whose task was to give lectures, organize study visits and meetings with the specialists, and to provide through these activities the students with the knowledge about pupils with 
SPIMD. They also supervised the creation of learning tools. The creation of learning tools was based on the following objectives: 1 ) to create new learning tools or improve the existing ones for the development of the cognitive skills of pupils with SPIMD; 2) to use innovative textile materials and textile-based solutions; 3) considering the study of the existing learning tools, to avoid the shortcomings that the currently used tools have; 4) to take into consideration the fact that the development of cognitive skills is closely connected with the development of motor skills, social and communicative skills, as well as skills for managing the everyday life; 5) it must be possible to combine the new tools with one another; 6) the products must be easy to clean; 7) there is no specific theme given. The students will find the idea based on their theoretical knowledge, the study of existing learning tools and their experience at the study visits.

Following the initial task, the students created eight designs for learning tools.

Touch-sensitive cloud/screen (author of design Stella Kalkun). The design was based on studies (Sahraie et al., 2006) which show that training with visual objects may lead to a better perception and awareness of these objects.

Tactile domino (author of design Kristel Laurits). The creation of the domino was based on the idea that when the contrasts between different surfaces regarding visual and tactile information coincide, the information from the two channels can be combined. In that case the tactile information supports the use of visual information and does not interfere with it (Hyvarinen, 1988, 35).

Therapeutic pillows The Rabbit/The Cat/The Octopus/The boy (authors of design Inna Beinar, Tatjana Kuusik). These are pillows of size $80 \times 70 \mathrm{~cm}$, with s simple shape and different fillings, from soft batting and granules to different grains which make the pillows different in terms of weight.

Pillows supporting development (author of design Liisa Aid). Similar pillows were in use also before, but they lacked the opening where the teacher can hide an object as stimuli that would motivate the pupil to look for it (by opening the zippers, buttons and other elements).

An arch/arch (author of design Imbi Ilves). In creating this learning tool, it was taken into account that children who have several severe sensory disabilities perceive the world within the reach of their arms (Estonian Ministry of Social..., 1995). Therefore, it is important that the concept of space and the perception of specific features of objects would start at this distance. The designer made a 'roof' from a light material under which a child can experience a private and safe environment.

Modules (author of design Luise Wonneberger, Germany). A precondition for learning is such a body posture that would better enable the use of the existing motor skills. The modules are covered with a cotton fabric on which contrasting patterns have been printed. The modules can be connected with one other with the help of magnets.

A cloud that amplifies sounds (author of design Kristel Laurits). It was taken into consideration that the focus of attention on identifying an object from among other objects can be more successful when the pop-out effect is used (amplifying the sound made).

A safe circle (author of design Anna Magidenko, Russia). The learning tool enables a safe and comfortable environment for learning and relaxing.

\section{Study 3: the assessment of designs for learning tools by the specialists working with pupils with SPIMD}

The evaluation of the learning tools was based on the drawings about them and the accompanying text. The specialists were first contacted by phone or in person. After that the drawings and the questionnaire had been sent them by e-mail. The designs were assessed by class teachers working with pupils with SPIMD $(n=6)$, a head teacher, speech therapists $(n=2)$, physiotherapists $(n=4)$ and psychologists $(n=2)$. The Likert scale was used in the questionnaire to assess the learning tools. The assessment was carried out in three categories: the novelty of the learning tool, the suitability of the tool for the needs of the pupil with SPIMD, and the readiness to use the tool in one's everyday work. In the second part of the questionnaire open questions were used. The specialists were asked to describe the positive and negative aspects of the learning tool, to point out the flaws, as well as other issues to consider in the future. Frequency tables and mean (Figure 2) were compiled in Excel, based on the assessments on the Likert scale. The answers of the open questions were analysed by using qualitative content analysis. 


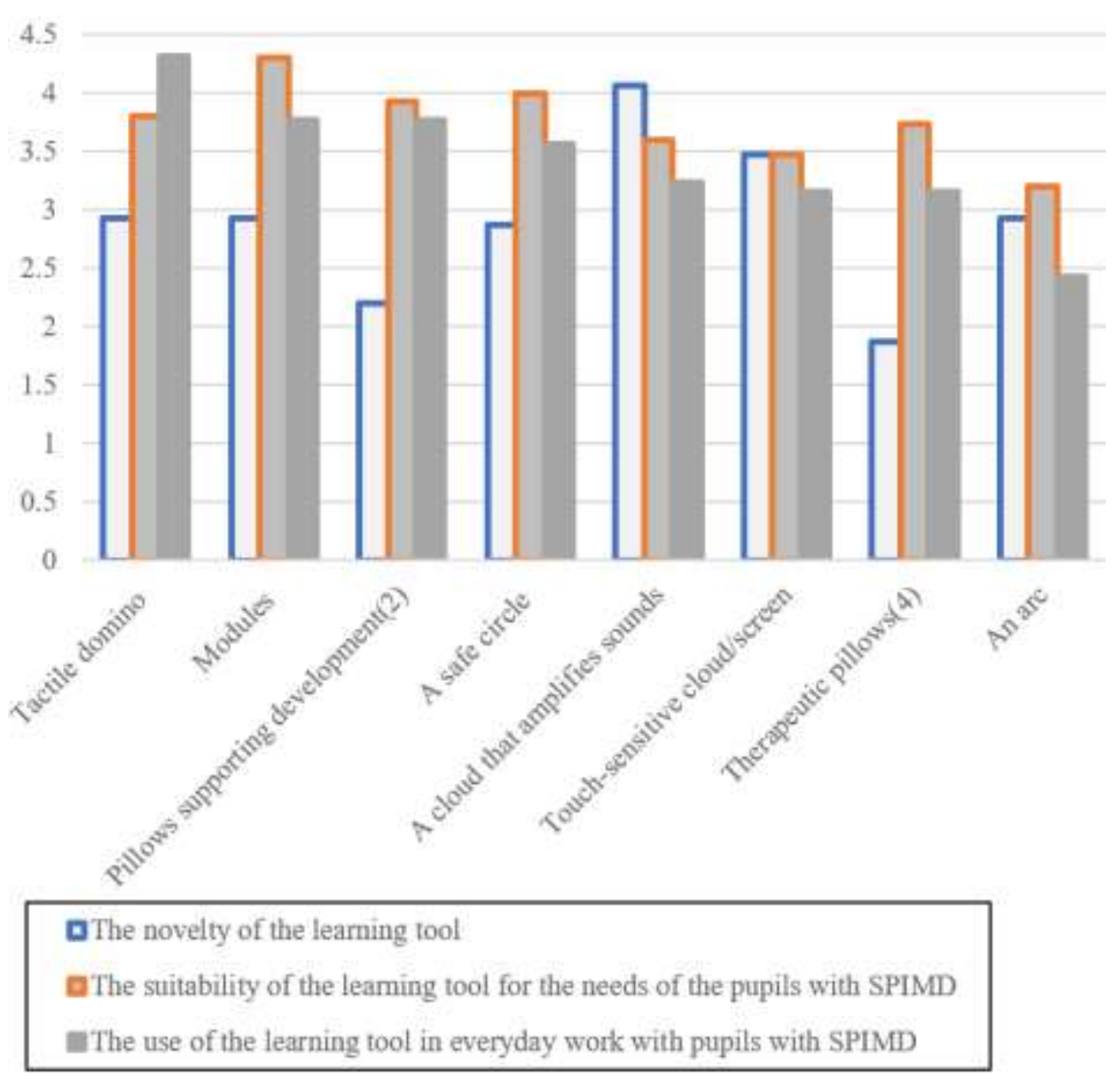

Figure 2. The assessment of designs for learning tools by the specialists working with pupils with SPIMD.

\section{The novelty of the learning tool}

The respondents had to assess the following statement: "The learning device is novel" on the Likert scale (5-fully novel, 1-nothing new about this tool). Lower values of the scale refer to the lack of novelty and higher values to considerable novelty. The middle value of the scale can be interpreted as "I cannot tell". Most of the specialists $(n=10)$ were not able to assess the novelty of the touch-sensitive cloud/screen which had an innovative technical solution. Technical innovativeness could actually be the reason for such an assessment, since it is hard to evaluate by only looking at the drawings. The cloud which amplifies sounds were considered by most respondents as novel. The other tools were assessed as lacking novelty. The initial task given to the designers was to create a new learning tool or improve the existing ones. Based on the results of the study it can be assumed that the improvements to the existing learning tools were not noticed; only the novelty of the ideas was assessed. The evaluations of the specialists differed a lot. The differences can be explained with different professional backgrounds of the respondents, their different understanding of the term 'novelty' as well as their different reading of the drawing on which the evaluations were based.

\section{The suitability of the learning tool for the needs of the pupils with SPIMD}

The respondents assessed the statement „The designer has understood the needs of pupils with SPIMD” on a Likert scale (5- has understood very well, 1-has not understood at all). The lower values on the scale refer to not taking into account the needs of the pupils with SPIMD and higher values to these needs having been considered. The middle value of the scale can be interpreted as "neither this nor that" In short, it can be said that the modules, the pillow supporting development, the safe circle and the therapeutical pillows were evaluated as meeting the needs of the pupils with SPIMD. In case of the arc/arch and the tactile domino, the specialists expressed contradictory opinions. The respondents were unable to assess the suitability of the touch-sensitive cloud/screen and the cloud amplifying sounds for the needs of the pupils with SPIMD. 


\section{The use of the learning tool in everyday work with pupils with SPIMD}

The statement "I would use the learning tool in my everyday work" was assessed by the respondents on a 5-point Likert scale (5- "would definitely like" to 1- "I do not need such a tool"). The lower values on the scale refer to the tool not to be used, and higher values to the willingness to use the tool in everyday work. The middle value of the scale be interpreted as "maybe I would use".

In short, it can be said that the special education teachers would use on a daily basis the tactile domino, the modules, the pillow supporting development and the safe circle. The physiotherapists would use the modules and the tactile domino. The speech therapists would need in their work the cloud which amplifies sounds and the arc/arch. The psychologists would use the tactile domino, the pillow supporting development, the arc/arch, the safe circle, and therapeutical pillows. The special education teachers added a note in the questionnaire about the technical solution of the arc/arch: „I wouldn't use for studying since the tool does not muffle the sound (too much background noise). The arch can collapse, the Velcro fastenings can just unfasten, and the things can get into the mouth and the nose". The doubt of special education teachers regarding the use of the arc/arch with a novel solution are justified. The learning tool would need testing as a prototype. In short, it can be said that novel things are very hard to notice by looking at drawings. Based on the study results it may be assumed that improvements to the existing learning tools were not always noticed; only the novelty of the idea was assessed the evaluations of the specialists regarding the novelty of the learning tools differed a lot. The differences can be explained with different disciplines of the respondents and with a different understanding of the term "novelty". Solutions similar to the currently used learning tools were assessed as meeting the needs of pupils with SPIMD. The neutral position was taken in evaluating innovative tools. This is the sign of the carefulness of the specialists in applying new solutions. This serves as the proof for the need for stronger cooperation between the designer and the specialists working with pupils with SPIMD. The operating principles of the tools with innovative technical solutions need to introduce to the specialists. Also, prototypes should be made.

In open questions the specialists were asked to name the positive and worrisome aspects of the tools created for pupils with SPIMD. It appears from the responses that a learning tool should be: multifunctional and easy to combine (thoroughness and user-centredness); child-friendly, playful; aesthetic, novel; safe; taking into account the concept of special needs; possible to improve; made of natural materials; offering new design solutions.

At the same time the concern was expressed about the safe use of electronic devices. Several questions about the care and cleaning of learning tools were asked. Since the assessment of the specialists was based on the drawings, the designer could take the specialists suggestions into account and improve the technical solution of the learning tool.

\section{Study 4: the prototypes and the evaluation of prototypes}

Bearing in mind the evaluations of the designs for learning tools by the specialists, it was taken into account that the target group for such product is not limited only to children with SPIMD, but these should be possible to use also by children with different special needs or normal development. Seven prototypes were made. There were no prototypes based on the safe circle, since the designer could not participate in the process of creating the prototypes. Photos of prototypes are available at Estonian Academy of Arts home page (Ilves et al., 2011).

The prototypes were given for using to the rehabilitation unit of TCH. The user experiences of the specialists working there give relevant feedback, since children on rehabilitation have a variety of very different needs, and it was important to see from the feedback, whether the tools created for SPIMD children could also be used with a wider target group. The prototypes are used on a daily basis by three specialists: two physiotherapists and one occupational therapist. Children with very different needs go to the therapy in the unit: a slight lag of sensory motor skills, patients with different neurological diagnoses and multiple disabilities (such as Dystrophia Musculorum Duchenne, Cerebral palsy, Morbus LangdonDown, Spina bifida, Hydrocephalus). Children attending the therapy are from 3 months to 21 years old. A therapy session lasts for 60 minutes (the number of children per day varies, since the length of the specialist's working day varies). Therapy is provided for children in out-patient care or those receiving inpatient rehabilitation in the neurological unit of the hospital. The work of specialists involves the development of motor skills and everyday skills, as well as cognitive skills of children. This makes it possible to receive varied user feedback. The interviews were conducted when the learning tools had been 
in use for 3-4 months and the condition of prototypes was controlled after three years of use. One of the therapists was interviewed on the phone, the other two in the therapy room. The interviews were carried out in different ways due to the busy schedule of the specialists.

The specialists' feedback to using the prototypes and the condition of prototypes after four years of use in Table 1. Additionally, the therapists emphasised the appropriate design: "I like the patterns and materials. If there is too much going on at the same time (there are already colourful therapy balls and mats in our room), then it gets confusing. Spots and stripes make the modules more fun. No one has asked, why there are no teddy bears, flowers or dolls depicted on them. I have also noticed that children tend to select simple items, not those that are varicoloured and do several things." When comparing the assessment of the designs with the use of the prototypes, it appeared that the specialists noticed the same shortcomings: the reliability of tools using electricity and the instability of the Arch, and it is apparent from the user experience of prototypes that when taking the needs of the SPIMD pupils into account when designing learning tools, such tools can also be used in a wider target group (Table 1).

Table 1

Specialist feedback on using prototypes

\begin{tabular}{|c|c|c|}
\hline $\begin{array}{c}\text { Title of the } \\
\text { learning } \\
\text { tool }\end{array}$ & $\begin{array}{l}\text { Who was the } \\
\text { prototype used } \\
\text { on }\end{array}$ & Observations \\
\hline $\begin{array}{l}1 . \\
\text { Tactile } \\
\text { domino }\end{array}$ & $\begin{array}{l}\text { Can be used } \\
\text { with all children, } \\
\text { but not suitable } \\
\text { for children who } \\
\text { bite things or put } \\
\text { things into their } \\
\text { mouth. }\end{array}$ & $\begin{array}{l}\text { Design (size, materials, colours and others): size }(8 \times 16 \times 1.5 \mathrm{~cm}) \text { is } \\
\text { suitable. It's easier to grasp blocks when they are attached to the base } \\
\text { (Velcro attachment). Blocks are very lightweight, but to get them off } \\
\text { the base, you need to apply some force, so very suitable for children } \\
\text { with muscular disorders. } \\
\text { Shortcomings discovered: the plastic fringe element is not durable. } \\
\text { Additions: there could be another colourful block to add even more } \\
\text { contrast. } \\
\text { Condition of prototypes after four years of use: currently in use, } \\
\text { prototype is working. }\end{array}$ \\
\hline $\begin{array}{l}2 . \\
\text { Modules }\end{array}$ & $\begin{array}{l}\text { Everyone, who } \\
\text { attend therapy } \\
\text { and have the } \\
\text { need. }\end{array}$ & $\begin{array}{l}\text { Design (size, materials, colours and others): children have noticed } \\
\text { stripes and spots; have combined several combinations (stripe and spot } \\
\text { and others). Textile cover has been very durable, has not been torn or } \\
\text { broken. The module's filling of half-stiff rubber foam is suitable, size } \\
\text { ( } 40 \text { x } 40 \text { x } 40 \text { and } 40 \text { x } 20 \text { x } 40 \mathrm{~cm} \text { ) and weight are suitable. } \\
\text { Shortcomings discovered: modules hold together well if placed on } \\
\text { therapy mat (on the floor, they start moving). } \\
\text { Additions: the attachment between modules should be stronger. For } \\
\text { sensory-motoric learning, there could be the possibility of attaching } \\
\text { covers of different materials (furry, rough, and others) to the modules, } \\
\text { and some modules could have different levels of stiffness. There could } \\
\text { be a longer "board that could also be used as a table". } \\
\text { Condition of prototypes after four years of use: currently in use, } \\
\text { prototype is working. Cover material is fine, but the magnetic fasteners } \\
\text { do not work, as the fasteners that had been selected did not correspond } \\
\text { to the magnetic force (magnets have been removed). }\end{array}$ \\
\hline $\begin{array}{l}3 . \\
\text { Pillows } \\
\text { supporting } \\
\text { deve- } \\
\text { lopment }\end{array}$ & $\begin{array}{l}\text { Suitable for } \\
\text { children with } \\
\text { motor skill } \\
\text { disorders. Very } \\
\text { young children }\end{array}$ & $\begin{array}{l}\text { Design (size, materials, colours): Size }(40 \times 28 \times 6 \mathrm{~cm}) \text { is suitable; } \\
\text { easy to use with two hands. Child with sensory disorder did not like } \\
\text { the material (artificial felt) } \\
\text { Shortcomings discovered: there was a pressed stud and a button; the } \\
\text { button came off. }\end{array}$ \\
\hline
\end{tabular}




\begin{tabular}{|c|c|c|}
\hline $\begin{array}{l}\text { Title of the } \\
\text { learning } \\
\text { tool }\end{array}$ & $\begin{array}{l}\text { Who was the } \\
\text { prototype used } \\
\text { on }\end{array}$ & Observations \\
\hline (2 pieces) & $\begin{array}{l}\text { (under } 2 \text { years of } \\
\text { age) showed no } \\
\text { interest in them }\end{array}$ & $\begin{array}{l}\text { Additions: the covers could be changeable and made from different } \\
\text { materials. } \\
\text { Condition of prototypes after four years of use: currently in use, } \\
\text { prototype is working }\end{array}$ \\
\hline $\begin{array}{l}4 . \\
\text { Thera- } \\
\text { peutic } \\
\text { pillows } \\
\text { (4 pieces) }\end{array}$ & $\begin{array}{l}\text { Suitable for all } \\
\text { patients, whose } \\
\text { body position } \\
\text { needs correcting } \\
\text { (e.g. lying on the } \\
\text { back, sitting) } \\
\text { Also suitable for } \\
\text { young children as } \\
\text { 'companions', } \\
\text { e.g. when } \\
\text { learning to walk; } \\
\text { 'animal helps to } \\
\text { walk' }\end{array}$ & $\begin{array}{l}\text { Design (size, materials, colours): The lack of details is not a problem: } \\
\text { children have not asked why the creature has no eyes. Measurements } \\
\text { are suitable }(80 \times 70 \mathrm{~cm}) \text {. Younger children touch the tactile elements } \\
\text { visible on the pillow, older children are interested in the tactile elements } \\
\text { that are "hidden" inside the item } \\
\text { Condition of prototypes after four years of use: currently in use, one } \\
\text { pillow is missing, but } 3 \text { are being used }\end{array}$ \\
\hline $\begin{array}{l}5 . \\
\text { A cloud } \\
\text { that } \\
\text { amplifies } \\
\text { sounds }\end{array}$ & & $\begin{array}{l}\text { Shortcomings discovered: It was impossible to use the prototype, as the } \\
5 \mathrm{~W} \text { Audio Amplifier Kit that was used is not a suitable solution } \\
\text { Additions: There should be a suitable solution to receive and amplify sound } \\
\text { Condition of prototypes after four years of use: not in use. technical } \\
\text { solutions were not durable }\end{array}$ \\
\hline $\begin{array}{l}6 . \\
\text { Touch- } \\
\text { sensitive } \\
\text { cloud/ } \\
\text { screen }\end{array}$ & & $\begin{array}{l}\text { Shortcomings discovered: Problems with fastening on the wall: as they } \\
\text { wanted to use the prototype both on the wall and on the table, the wall } \\
\text { attachments could not hold up with the change of position. Switching } \\
\text { the device off partially with current switches is not a suitable way of } \\
\text { doing that. The LED screen can only be seen well in a dark room } \\
\text { Additions: There should be the possibility of adding different covers to } \\
\text { the switches (different colours, tactile elements) There should be } \\
\text { solutions to technical shortcomings (attachments, suitable switches, } \\
\text { more powerful source of light) } \\
\text { Condition of prototypes after four years of use: not in use: problems } \\
\text { with the technical solution. }\end{array}$ \\
\hline $\begin{array}{l}7 . \\
\text { An arc }\end{array}$ & & $\begin{array}{l}\text { Design (size, materials, colours): the use of light material is suitable } \\
\text { Shortcomings discovered: the arc failed to stand in a stable upright position. } \\
\text { The base of the arc }(195 \times 150 \mathrm{~cm}) \text { is too narrow, children cannot really fit } \\
\text { underneath } \\
\text { Additions: to improve the technical solution, to ensure stable upright } \\
\text { position } \\
\text { Condition of prototypes after four years of use: Not in use: problems with } \\
\text { keeping a stable upright position. A suitable solution has not been found }\end{array}$ \\
\hline
\end{tabular}

To date, there has been no in-depth study into the needs of SPIMD students in Estonia; this is the first interdisciplinary approach to creating learning tools for SPIMD students. This article is based on a research focusing on the following problem: the needs of pupils have not been considered when 
creating tools supporting learning. The research shows that learning tools do not always provide clear and strong stimuli for pupils: learning tools are too diverse; in photos and pictures, the figure cannot be distinguished from the background and auditory learning tools suffer from poor sound quality. It can be concluded from the results of the study that learning tools of inappropriate design (visual, tactile or auditory) do not support understanding the topic that is taught. J. Brodin (1999) also argues that if children with profound multiple disabilities get the right stimuli (i.e. adapted toys corresponding to their developmental level and a stimulating and supportive environment), they are not passive.

It results from this research that in Estonia, at schools teaching SPIMD pupils, the toys meant for young children are widely used. Based on the current paper, it can be concluded that the toys that are being used do not even meet the requirements of young children, being of poor quality and not considering the aesthetic requirements. These toys are not suitable for using with SPIMD pupils either, as these do not correspond to their age. In addition, toys meant for children often have very small buttons and switches, which makes using these items difficult or impossible with SPIMD pupils, as they have limited fine motor skills and the measurements of their hands are significantly larger than the hands of small children. Pupils have difficulties with grasping and holding items. Therefore, toys first need to be assessed regarding their quality and after that they can be adapted to be used by children with special needs. Research on infants' toys has found that only $5 \%$ of the toys analysed are actually accessible for children with hearing, motor and visual impairment and did not require any adaptation or help to be played (Perino, 2017). The students, who participated in the study, thought that actually it's not just the problem of the special school, rather a general thing about toys- screaming, whining things with unclear functions. By analysing the toys more closely, E.O. Smirnova (2011) finds similar that "the best of designs and the toy's potential usefulness can be devalued by its low quality; toys should not break easily and should correspond to the child's age". As recommended by C.G. Simpson and S.A. Lynch (2003), although the selection of appropriate toys holds a significant role in developing positive play experiences for young children, it may be necessary to adapt toys and materials to increase learning and social interactions for children with disabilities. Most adaptations revolve around issues regarding toy stabilization, toy extensions, toy attachment, and toy confinement. S. Doctoroff (2001) notes that all young children can play with the same play materials. However, in some instances play materials that meet the motor or sensory needs of children with disabilities will need to be specifically selected or existing toys and materials will need to be adapted. When we talk about SPIMD child's progress and development must know that they need personalised environmental changes (Caprino, Stucci, 2017).

All persons with SPIMD, should be considered visually impaired until proved otherwise (Van Splunder et al., 2006; Broek et al., 2006). The conducted study showed that suitable design for partially sighted persons has not been implemented in the existing learning tools.

The author opines that in creating new learning tools, it should be considered that most SPIMD pupils are visually impaired. It needs to be highlighted that the learning tools to be created need to be adjustable according to the special needs and individuality of pupils. Therefore, it is essential to understand the necessity of implementing user-oriented and universal design. It can be seen from the user experience of prototypes that by considering the needs of SPIMD pupils when creating learning tools, the tools can be used in wider target groups as well. This is not the case the other way around - unadjusted toys intended for small children cannot be used as learning tools in case of SPIMD persons. Taking account of the previous research and based on the results of our study, in creating new learning tools it should be taken into account that the product has to be of high quality and reliable; it has to consider the special characteristics of the cognitive processes and the underdeveloped motor skills of the pupils with SPIMD; it has to be universal, allowing adjustments according to individual special needs, it has to be easy to clean. It resulted from the study that the specialists' assessment on the design coincided with the assessment given to prototypes. This result gives reason to assume that more attention should be paid to the designing stage, and it would be a good idea to give the designer a specific task (exact description of what is needed). At the same time, however, it could also hinder the creation of truly innovative tools. Is important to know, that children with SPIMD need support that facilitates their ability to observe and to enter in contact with their children, helping them to propose stimulating activities and to interact in the most appropriate manner, without replacing them (Caprino, Stucci, 2017). J. Brodin (1999) finds that if children with profound multiple disabilities get the right stimuli (i.e. adapted toys corresponding to their developmental level and 
a stimulating and supportive environment), they are not passive. Therefore, it is of upmost importance to create learning tools that would take the needs of SPIMD into consideration.

\section{Conclusions}

The existing learning tools were assessed by specialists working with pupils with PIMD on a daily basis. It appeared that:

- three groups of tools can be distinguished that are used in the development of SPIMD pupils' cognitive skills: musical instruments, toys and self-made learning tools;

- currently, these tools do not take into consideration the individual needs of these children; the tools are often of poor quality and not adapted to the special needs of the pupils.

The problem with the toys are:

- their quality is poor;

- they are not age-appropriate (meant for babies and infants);

- colours and design: The toys are 'too colourful' and of unsuitable colour (a blue bear, pink elephant). In the photos and pictures the figures do not stand out from the background (shiny, no contrast and other);

- regarding auditive toys, bad sound quality and the lacking possibility to regulate the volume were emphasised;

- products for infants have often very small buttons and switches which make them hard or impossible to use for children with PIMD (inadequate/deficient fine motor skills and a considerably larger hand size compared to infants). Pupils experience difficulties in grasping and holding such tools;

- many pupils with PIMD have uncontrollable salivation, or the pupils try to 'stick things in their mouth and bite them'. Bearing this in mind, the learning tools should be of very good quality and easy to clean.

In creating new learning tools, it should be taken into account that the product:

- it must be considered that the development of cognitive skills is closely connected to the development of motor, social, daily and communicative skills;

- must consider the special characteristics that arise from the cognitive process of pupils with SPIMD (e.g., in differentiating between sense stimuli);

- must be high-quality, durable and easily cleaned;

- must be possible to operate the buttons, switches, attachments even with deficient fine motor skills;

- must be universal and adaptable to an individual's special needs.

Learning tools with unsuitable design (visual, tactile as well as auditive) do not support the understanding of what is being taught. In the process of creating learning tools, there should be cooperation between specialists working with SPIMD pupils, neuroscientists, designers, engineers, producers and others. According to the specialists participating in this study, such cooperation would allow creating "truly innovative products" and an interdisciplinary approach to the creation of learning tools can to a considerable extent support the learning of different essential skills by the pupils with SPIMD.

\section{Bibliography}

1. Bellamy G., Croot L., Bush A., Berry H., Smith, A. (2010). A study to define: Profound and multiple learning disabilities (PMLD). Journal of Intellectual Disabilities, 14(3), 221-235.

2. Brodin J. (1999). Play in Children with Severe Multiple Disabilities: Play with toys - a review. International Journal of Disability, Development and Education, 46(1), 25-34.

3. Broek E.C., Janssen C.C., Ramshorst T., Deen L. (2006). Visual impairments in people with severe and profound multiple disabilities: An inventory of visual functioning. Journal of Intellectual Disability Research, 50(6), 470-475.

4. Caprino F., Stucci V. (Eds.). (2017). Play in Children with Multiple Disabilities. In S. Besio, D. Bulgarelli, V. Stancheva- Popkostadinova, Play development in children with disabilities. Warsaw/Berlin: De Gruyter Open Ltd, 147-154. 
5. Carnaby S. (2007). Developing Good Practice in the Clinical Assessment of People with Profound Intellectual Disabilities and Multiple Impairment. Journal of Policy and Practice in Intellectual Disabilities, 4(2), 88-96.

6. Colley A. (2013). Personalised learning for young people with profound and multiple learning difficulties. London and Philadelphia: Jessica Kingsley Publishers.

7. Doctoroff S. (2001). Adapting the Physical Environment to Meet the Needs of "All" Young Children for Play. Early Childhood Education Journal, 29(2), 105-109.

8. Estonian Education Information System. (2018). The Ministry of Education and Research. Retrieved from http://www.ehis.ee/ (in Estonian)

9. Estonian Ministry of Social Affairs. (1995). Vaimupuudelaste opetamise metoodikamaterjalid, II osa: kognitiivsed oskuse d (Teaching methodology for pupils with intellectual disabilities, Part II: Cognitive skills). Estonia: Tallinn. (in Estonian)

10. Evenhuis H.M., Theunissen M., Denkers I., Verschuure H., Kemme H. (2001). Prevalence of visual and hearing impairment in a Dutch institutionalized population with intellectual disability. Journal of Intellectual Disability Research, 45(5), 457-464.

11. Fischer K.W. (2009). Mind, Brain, and Education: Building a Scientific Groundwork for Learning and Teaching. Mind, Brain and Education, 3(1), 3-16.

12. Human centred design for interactive systems. (2010). ISO 9241-210:2010. Geneva, Switzerland: International Organization of Standartization (ISO).

13. Hyvarinen, L. (1988). Vision in Children: Normal and Abnormal. Meaford, Ontario, Canada: The Canadian Deaf-Blind and Rubella Association. Retrieved from https://archive.org/details/visioninchildren00leah

14. Ilves I., Aid L., Kuusik T., Kalkun S., Laurits K., Beinar I., Wonneberger L. (2011). Oppe ja teraapia vahendid liitpundega lastele (Interactive study - and therapy tools). Tallinn: Estonian Academy of Arts. Retrieved from https://issuu.com/locomotiiv/docs/trykk teraapiavahendid brozyyr (in Estonian)

15. Murphy G., Carr J., Callias M. (1986). Increasing simple toy play in profoundly mentally handicapped children: II Designing special toys. Journal of Autism and Developmental Disorders, 16(1), 45-58.

16. Nakken H., Vlaskamp C. (2007). A Need for a Taxonomy for Profound Intellectual and Multiple Disabilities. Journal of Policy and Practice in Intellectual Disabilities, 4(2), 83-87.

17. Perino O. (2017). Play, Toys and Low Technology. The First LUDI Training School. Play and Toys for All. Heerlen, The Netherlands: Zuyd University.

18. Pohikooli lihtsustatud riiklik oppekava (Simplified curriculum of the Estonian basic school). (2010). Riigi Teataja, 1(14). Retrieved from https://www.riigiteataja.ee/akt/128122010014 (in Estonian)

19. Rebelo F., Soares M.M. (2012). Advances in Usability Evaluation, Part II. FL, Boca Raton: CRC Press Taylor and Francis Group.

20. Safter D. (2007). Designing for interaction: Creating smart applications and clever devices. Berkeley, CA: AIGA Design Press.

21. Sahraie A., Trevethan C.T., MacLeod M.J., Murray A.D., Olson J.A., Weiskrantz L. (2006). Increased sensitivity after repeated stimulation of residual spatial channels in blindsight. Proceedings of the National Academy of Sciences (PNAS), 103(40), 14971-14976.

22. Simpson C.G., Lynch S.A. (2003). Adapting and Modifying Toys for Children with Special Needs. Retrieved from https://files.eric.ed.gov/fulltext/ED481092.pdf

23. Smirnova E.O. (2011). Psychological and educational evaluation of toys in Moscow Centre of Play and Toys. Psychological Science and Education, 2, 5-10.

24. Van Splunder J., Stilma J.S., Bernsen R.D., Evenhuis H.M. (2006). Prevalence of visual impairment in adults with intellectual disabilities in the Netherlands: cross-sectional study. Eye, 20(9), 1004-1010.

25. World Health Organization. (2014). International Statistical Classification of Diseases and Related Health Problems 10th Revision (ICD-10)-2014-WHO Version for; 2014, Chapter V Mental and behavioural disorders (F00-F99). Retrieved from http://apps.who.int/classifications/icd10/browse/2014/en\#/F70-F79 